\title{
Effects of amantadine and topiramate on neuronal damage in rats with experimental cerebral ischemia-reperfusion
}

\author{
Zahide Betül Gündüz ${ }^{1, A-F}$, Filiz Aktas ${ }^{1, A}$, Husamettin Vatansev ${ }^{2, C}$, Merve Solmaz ${ }^{3, C}$, Ender Erdoğan $3, B, C$ \\ ${ }^{1}$ Department of Neurology, Saglık Bilimleri University, Konya City Hospital, Turkey \\ ${ }^{2}$ Department of Biochemistry, Faculty of Medicine, Selçuk University, Konya, Turkey \\ ${ }^{3}$ Department of Histology and Embryology, Medical Faculty, Selçuk University, Konya, Turkey \\ A - research concept and design; B - collection and/or assembly of data; C - data analysis and interpretation; \\ $D$ - writing the article; $E$ - critical revision of the article; $F$ - final approval of the article
}

\section{Address for correspondence}

Zahide Betül Gündüz

E-mail:drzahidebetul@yahoo.com

Funding sources

This study was funded by the Saglık Bilimleri University Research Projects Fund Committee (grant No. 2019/032-04/04/2019).

Conflict of interest

None declared

Acknowledgements

We thank Prof. Dr. Yavuz Koksal for advice

on statistical analyses.

Received on March 28, 2021

Reviewed on May 17, 2021

Accepted on May 31, 2021

Published online on September 9, 2021

Cite as

Gündüz ZB, Aktas F, Vatansev H, Solmaz M, Erdoğan E. Effects of amantadine and topiramate on neuronal damage in rats with experimental cerebral ischemia-reperfusion. Adv Clin Exp Med. 2021;30(10):1013-1023.

doi:10.17219/acem/138327

DOI

10.17219/acem/138327

Copyright

Copyright by Author(s)

This is an article distributed under the terms of the

Creative Commons Attribution 3.0 Unported (CC BY 3.0)

(https://creativecommons.org/licenses/by/3.0/)

\begin{abstract}
Background. Ischemia-reperfusion models are used to evaluate treatment options that may minimize cellular damage after ischemia.

Objectives. To investigate the effects of amantadine and topiramate on apoptosis and cellular oxidative damage.

Materials and methods. This experiment was performed using 30 male Wistar albino rats. The right internal carotid artery was identified and clamped with an aneurysm clip under general anesthesia, except for animals in the control group. After 10 min of occlusion, the aneurysm clip was removed, allowing reperfusion. After reperfusion and a waiting period of $12 \mathrm{~h}$, the test and control groups were intraperitoneally administered the following solutions: the sham group received $10 \mathrm{mg} / \mathrm{kg}$ of isotonic solution, the amantadine group received $20 \mathrm{mg} / \mathrm{kg}$ of amantadine, the topiramate group received $40 \mathrm{mg} / \mathrm{kg}$ of topiramate, and the amantadine-topiramate group received $20 \mathrm{mg} / \mathrm{kg}$ of amantadine and $40 \mathrm{mg} / \mathrm{kg}$ of topiramate. After $24 \mathrm{~h}$, the rats were euthanized.
\end{abstract}

Results. Apoptosis was evaluated using the TUNEL method. Total antioxidant status (TAS), total oxidant status (TOS), total thiol, and ischemia-modified albumin (IMA) levels were measured in both brain tissue and serum samples. The rate of apoptosis in the sham and amantadine groups increased significantly compared to the control group and the non-ischemic counter hemisphere. In the amantadine-topiramate group, both serum TAS and tissue thiol levels decreased. Tissue TOS levels were significantly higher in the topiramate group compared to all other test groups. Tissue TAS levels were significantly higher in the amantadine group compared to all other test groups.

Conclusions. This experimental ischemia-reperfusion model revealed that topiramate reduces apoptosis in the early period after ischemia and that its combination with amantadine does not provide additional benefits against cell death. However, topiramate did not have an inhibitory effect on the oxidative stress biomarkers used in our study (TAS, TOS, IMA, and thiol). Studies that reveal the neuroprotective mechanism of action and long-term effects of topiramate are needed to complement this study.

Key words: topiramate, amantadine, apoptosis, oxidative stress, cerebral ischemia-reperfusion 


\section{Background}

Despite many positive developments in the diagnosis and treatment of cerebrovascular disease, it continues to be a significant cause of morbidity and mortality worldwide. Experimental stroke models are valuable because they can reveal important information about the biochemical and pathological changes that ischemia causes in cerebral tissue, and guide treatment options that act through these mechanisms.

Ischemia triggers apoptosis in cerebral tissue, leading to apoptotic cell death. This involves 2 pathways: the intrinsic pathway, which is associated with mitochondrial release and caspase- 3 stimulation of cytochrome c, and the extrinsic pathway, which leads to caspase- 8 stimulation as a result of activation of cell surface death receptors. The developing ischemia destroys the cells that perform essential functions, such as oxygen transport, glucose production and maintenance of neuronal ionic gradients. Rapid depletion of energy after cerebral ischemia leads to loss of membrane potential and depolarization of nerves. The voltage-dependent $\mathrm{Ca}^{+}$channels are then activated, and stimulating amino acids are released into the extracellular space. It is thought that cytotoxic accumulation of intracellular $\mathrm{Ca}_{2}{ }^{+}$then initiates a series of cytoplasmic and nuclear events, which primarily trigger the intrinsic apoptotic pathway.

Glutamate accumulates outside of cells during ischemia, binding to and opening a group of cation channels on the cell surface. Previous ischemic stroke research has largely concentrated on these receptors. The binding of glutamate to these ionotropic N-methyl-d-aspartate (NMDA) and $\alpha$-amino-3-hydroxy-5-methyl-4-isoxazolpropionic acid (AMPA) receptors promotes a further increase in $\mathrm{Ca} 2^{+}$input. Intracellular $\mathrm{Ca}_{2}^{+}$accumulation is a key step in cell death.

Reactive oxygen species (ROS) activity increases after ischemia and plays an important role in cell death in cerebral ischemia. Under physiological conditions, ROS, including superoxide anions $\left(\mathrm{O}_{2}^{-}\right)$, hydrogen peroxide $\left(\mathrm{H}_{2} \mathrm{O}_{2}\right)$ and hydroxyl radicals $\left(\mathrm{OH}^{-}\right)$, are produced at low levels and are crucial in signaling and metabolic pathways. The overproduction of ROS after ischemia, coupled with the inactivation of antioxidant enzymes and the consumption of antioxidants, leads to the failure of natural defense mechanisms in protecting neurons from oxidative damage. This increase in ROS is thought to cause destruction by directly affecting cellular proteins, lipids and DNA, or indirectly, by damaging normal cellular signaling and gene regulation. Although many of the key apoptotic proteins have been identified, understanding of the complex underlying mechanisms remains poor; thus, treatment of stroke patients by manipulating apoptotic pathways is an intensively studied subject. ${ }^{1}$

Based on the theory that NMDA receptor ion channels increase entry of $\mathrm{Ca}_{2}{ }^{+}$into cells, memantine, an NMDA receptor blocker, was used in ischemia-reperfusion studies and was shown to cause a decrease in apoptotic cell numbers and oxidant levels. This result supports the hypothesis that memantine is neuroprotective. ${ }^{2}$

Amantadine is an NMDA receptor antagonist. It is commonly used in antiparkinsonian treatment as a dopamine agonist, and there are clinical studies showing that it accelerates the rate of functional recovery in patients with post-traumatic consciousness disorders. ${ }^{3-5}$ Topiramate, another therapeutic agent, has a blocking effect on AMPA receptors, which increases intracellular $\mathrm{Ca} 2{ }^{+}{ }^{6}$ In an experimental spinal cord trauma model, topiramate accelerated recovery and was concluded to have a neuroprotective effect. ${ }^{7}$ Although many factors contribute to neuronal damage in ischemia, the pathogenesis has not yet been fully elucidated. The idea that a single medical treatment will be sufficient for treating neuronal ischemic pathogenesis seems overly optimistic.

\section{Objectives}

We aimed to investigate the effects of topiramate and amantadine on cell death and oxidative damage in an ischemic stroke model, with the prediction that combination therapy would increase the chance of success.

\section{Materials and methods}

\section{Animals}

A total of 30 male Wistar albino rats were used in this study, each weighing 450-500 g. Rats were housed in a controlled environment of $22^{\circ} \mathrm{C}$ with $12 \mathrm{~h}$ light and dark cycles. Standard laboratory rat food and water were provided. All animals received humane care in compliance with the Guide for the Care and Use of Laboratory Animals published by the Ethics Council of Selçuk University (Konya, Turkey). This study was performed at the Selçuk University Experimental Medicine Application and Research Center. The study protocol was approved by the Selçuk University Medical Faculty Ethics Committee (approval No. 2019/01$25 / 01 / 2019$ ) and the study was funded by the Health Sciences University Research Projects Fund Committee (grant No. 2019/032-04/04/2019).

\section{Ischemia-reperfusion model}

Rats were randomly divided into 5 groups (6 rats per group): control (C) group, sham (S) group, amantadine (A) group, topiramate $(\mathrm{T})$ group, and amantadine-topiramate (AT) group. General anesthesia was induced with intraperitoneal ketamine (Ketalar 500 mg; Pfizer, New York, USA) at $50-75 \mathrm{mg} / \mathrm{kg}$ and $2 \%$ xylazine (Xylazinbo $2 \%$; Bioveta, Katowice, Poland) at $5 \mathrm{mg} / \mathrm{kg}$. Rats were kept in a supine position and their necks were shaved. Following a midline 


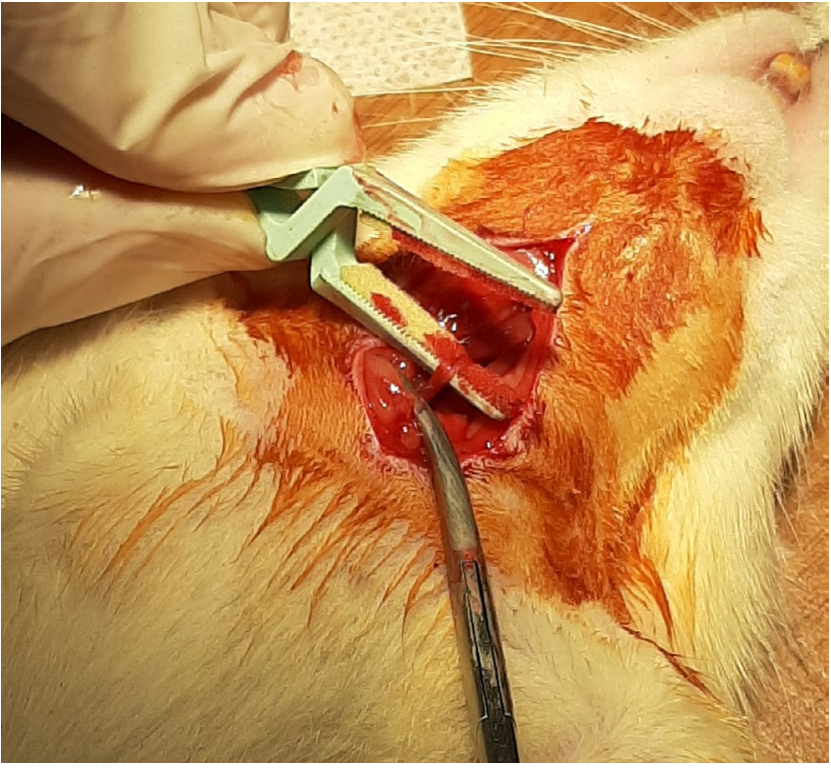

Fig. 1. Left internal carotid artery clamped with an aneurysm clip

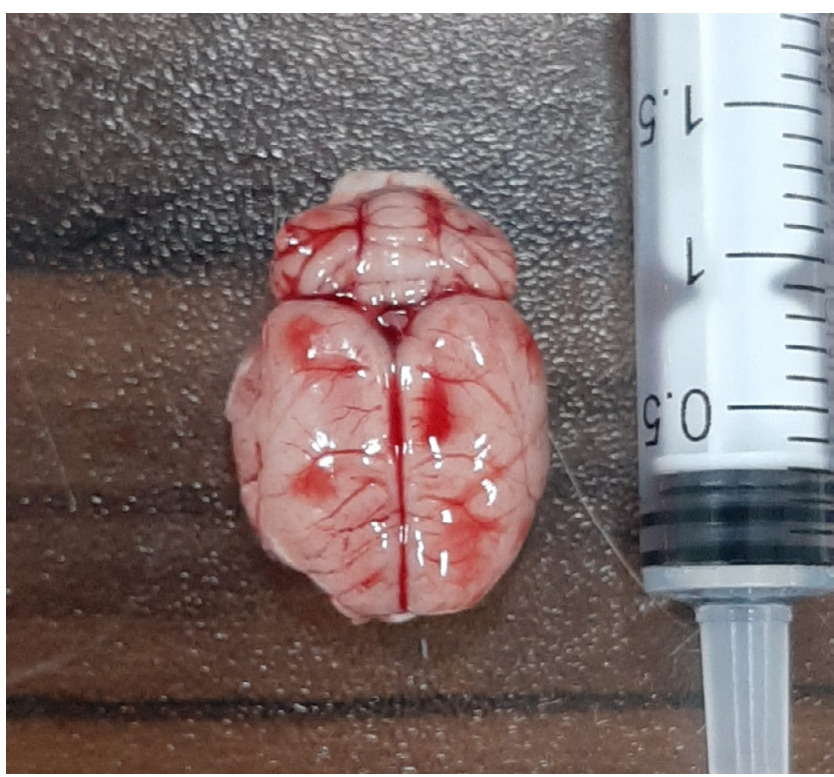

Fig. 2. Ischemic and non-ischemic zones of the brain

incision, the right internal carotid artery was identified and clamped with an aneurysm clip (Fig. 1). After $10 \mathrm{~min}$ of occlusion, the aneurysm clip was removed for reperfusion. Incisions were sutured with absorbable sutures. In control group animals, the same surgical procedure was performed, but the internal carotid artery was not clamped. ${ }^{2,8}$ After reperfusion and a $12 \mathrm{~h}$ waiting period, the following solutions were intraperitoneally administered to the groups: $10 \mathrm{mg} / \mathrm{kg}$ of isotonic solution (S group), $20 \mathrm{mg} / \mathrm{kg}$ of amantadine (A group), $40 \mathrm{mg} / \mathrm{kg}$ of topiramate (T group), and $20 \mathrm{mg} / \mathrm{kg}$ of amantadine and $40 \mathrm{mg} / \mathrm{kg}$ of topiramate (AT group). After $24 \mathrm{~h}$, the rats were euthanized under general anesthesia. Biopsies were performed on ischemic and non-ischemic brain zones and intracardial serum samples were taken (Fig. 2).

\section{TUNEL method}

Tissue samples were placed in freshly prepared $4 \%$ paraformaldehyde solution (95\% powder; Sigma 158127; SigmaAldrich, St. Louis, USA) with a fixative/tissue ratio of 10/1 and incubated at $4^{\circ} \mathrm{C}$ for at least $24 \mathrm{~h}$. Samples were then transferred to $30 \%$ sucrose solution prepared in phosphatebuffered saline (PBS; tablet; Sigma P4417; Sigma-Aldrich) and maintained for at least $24 \mathrm{~h}$. A cryostat device (Thermo Shandon Cryostat 210160GB; Thermo Fisher Scientific, Waltham, USA) was used to prepare 4- $\mu$ m-thick serial sections, which were stored at $-18^{\circ} \mathrm{C}$. The terminal deoxynucleotidyl transferase dUTP nick end (TUNEL) method, a common cellular marking method that detects DNA fragmentation by marking the 3'-hydroxyl terminals in double chain DNA fractures during apoptosis, was used to detect apoptosis. A TUNEL kit (ABP Bioscience-TUNEL Andy Fluor TM 488 Apoptosis Detection Kit cat = A050; Bioscience International, Rockville, USA) was used according to the protocol recommended in the prospectus. Closure was performed with a nonspecific nuclear marker, namely, the DAPI closure medium (UltraCruz ${ }^{\circledR}$ Aqueous Mounting Medium with DAPI, sc-24941; Santa Cruz Biotechnology, Santa Cruz, USA). Preparations were digitally viewed. Cells positively stained with TUNEL and all nuclei stained nonspecifically with DAPI were counted at different times by 2 different investigators using a double-blind protocol. Photographs of 4 areas were randomly taken for each tissue preparation. The following formula was used to calculate the apoptotic cell percentage (Fig. 3,4):

\section{apoptotic index $(\mathrm{AI})=$}

(TUNEL-positive cell number/total cell number) $\times 100$.

\section{Biochemical analyses}

Rat blood and brain tissue samples were collected for measurement of total antioxidant status (TAS), total oxidant status (TOS) and total thiol. Blood samples were centrifuged at $3000 \mathrm{rpm}$ for $10 \mathrm{~min}$. Plasma was collected and stored at $-80^{\circ} \mathrm{C}$. Brain tissue was homogenized with $0.05 \mathrm{~mol} / \mathrm{L}$ Tris- $\mathrm{HCl}$ buffer. To reduce stabilized proteins, a solution containing $0.015 \mathrm{~mol} / \mathrm{L}$ sodium azide (DAKO antibody diluent with background reducing components; Dako, Santa Clara, USA) was used and homogenized in a homogenizer (WiseTis HG-150; Daihan, Seoul, South Korea). Tissue homogenates were centrifuged at $3000 \mathrm{rpm}$ for $20 \mathrm{~min}$. The supernatant was collected and stored at $-80^{\circ} \mathrm{C}$. The TAS, TOS and total thiol values were measured in rat plasma and brain tissue samples using enzymelinked immunosorbent assay (ELISA; YL Biont, Shanghai, China). To do so, 96-well enzyme-linked immunosorbent assay (ELISA) plates were coated with antibody. Next, $40 \mu \mathrm{L}$ of sample, $10 \mu \mathrm{L}$ of antibody and $50 \mu \mathrm{L}$ of streptavidinhorse radish peroxidase (streptavidin-HRP) were sequentially added; $50 \mu \mathrm{L}$ of chromogen A and chromogen B were 


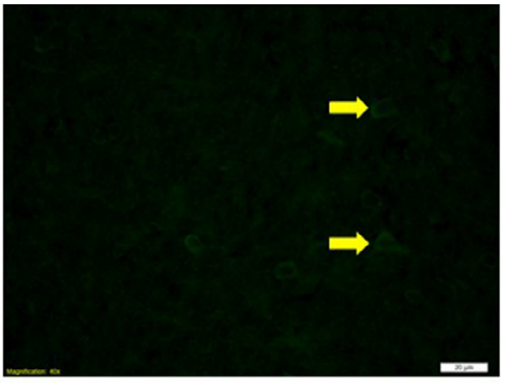

$\mathrm{A}-1 \mathrm{C}$ ischemic TUNEL

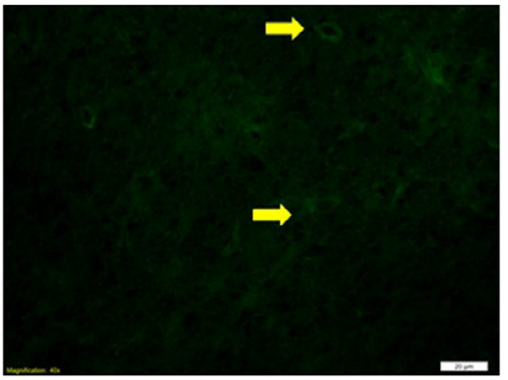

B-1 C non-ischemic TUNEL

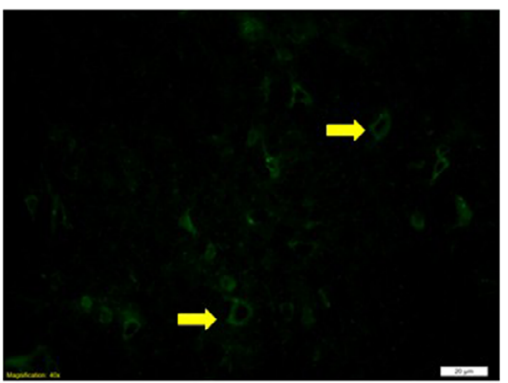

C-1 S ischemic TUNEL

$\Rightarrow$

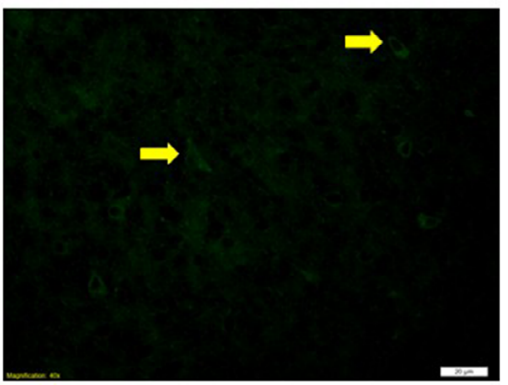

D-1 S non-ischemic TUNEL

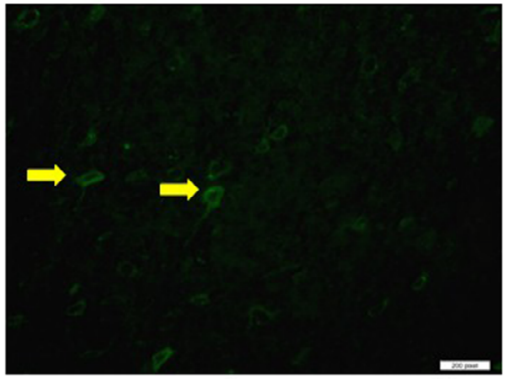

$\mathrm{E}-1 \mathrm{~A}$ ischemic TUNEL

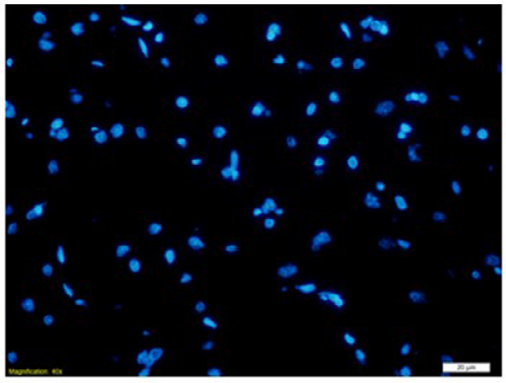

A-2 C ischemic DAPI

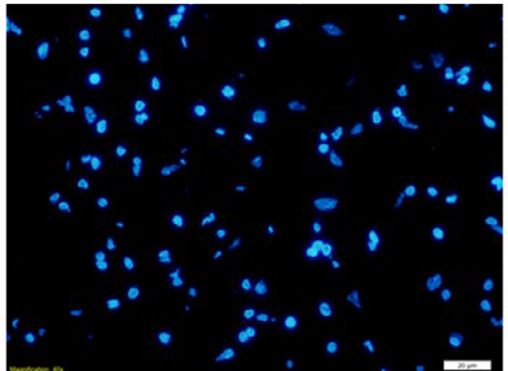

B-2 C non-ischemic DAPI

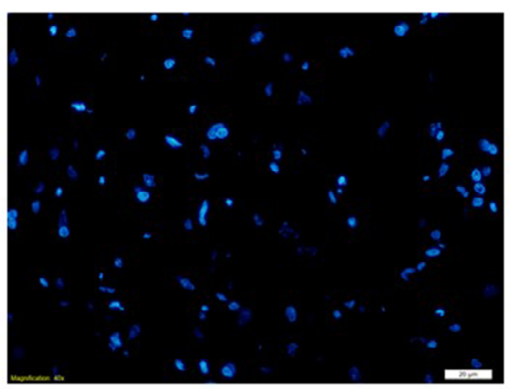

C-2 S ischemic DAPI

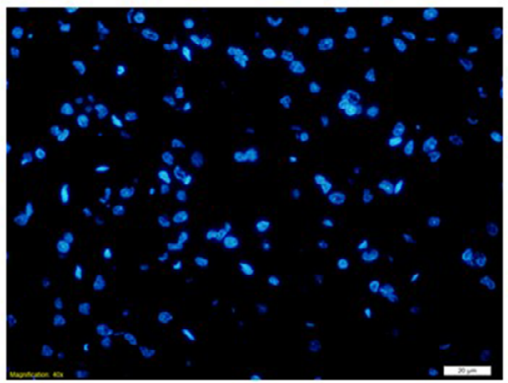

D-2 S non-ischemic DAPI

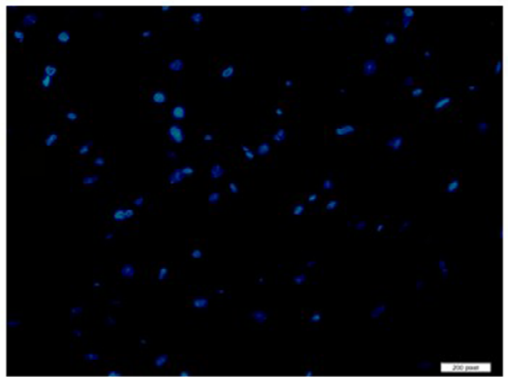

$\mathrm{E}-2 \mathrm{~A}$ ischemic DAPI

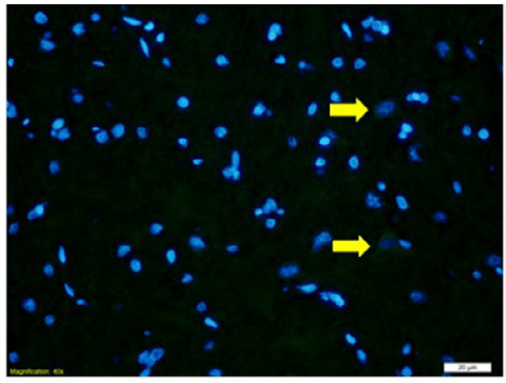

$\mathrm{A}-3 \mathrm{C}$ ischemic merge

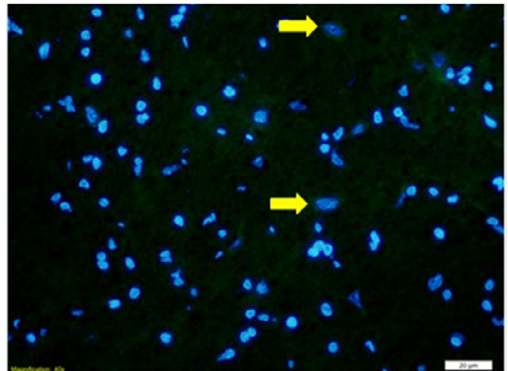

B-3 C non-ischemic merge

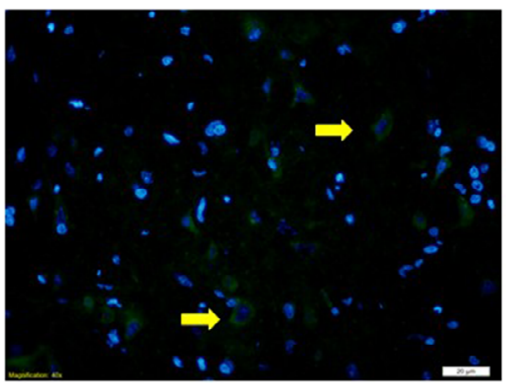

C-3 S ischemic merge

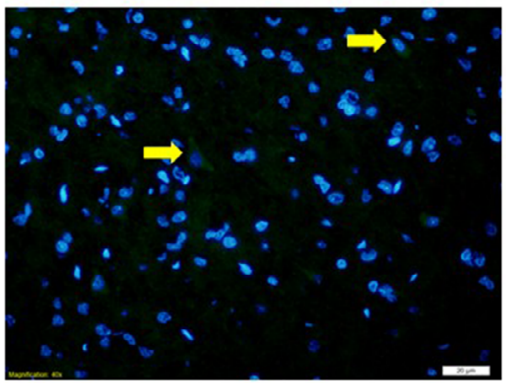

D-3 S ischemic merge

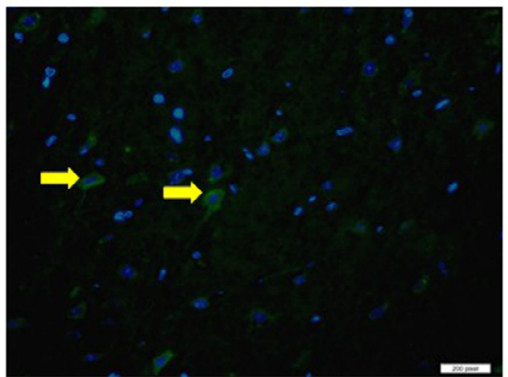

$\mathrm{E}-3 \mathrm{~A}$ ischemic merge

C - control group; $S$ - sham group; $A$ - amantadine group

Fig. 3. Frontal cortex TUNEL (apoptosis), DAPI (nuclear marker) and merge (TUNEL+DAPI) images. A. 1,2,3 - control ischemic TUNEL, DAPI, merge; B. 1,2,3 - control non-ischemic TUNEL, DAPI, merge; C. 1,2,3 - sham ischemic TUNEL, DAPI, merge; D. 1,2,3 - sham non-ischemic TUNEL, DAPI, merge; E. 1,2,3 - amantadine ischemic TUNEL, DAPI, merge. * yellow arrows indicate TUNEL-positive cells 


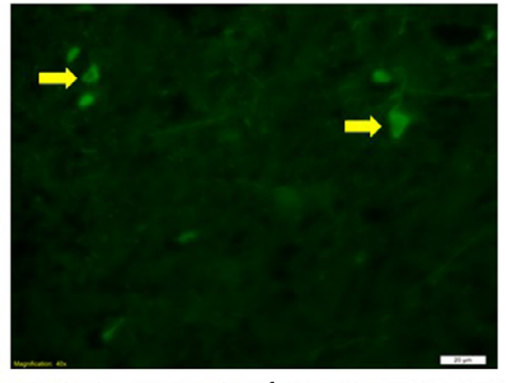

F-1 A non-ischemic TUNEL

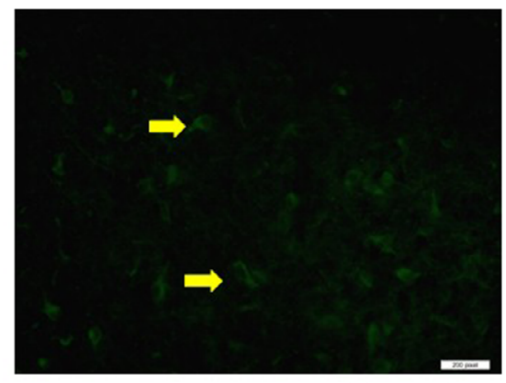

G-1 T ischemic TUNEL

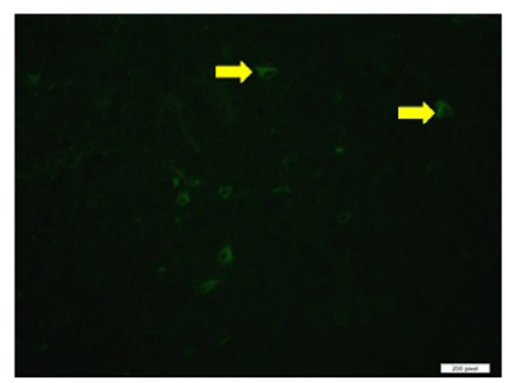

H-1 T non-ischemic TUNEL

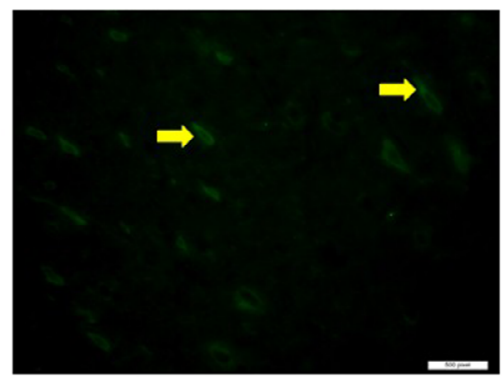

I-1 A+T ischemic TUNEL

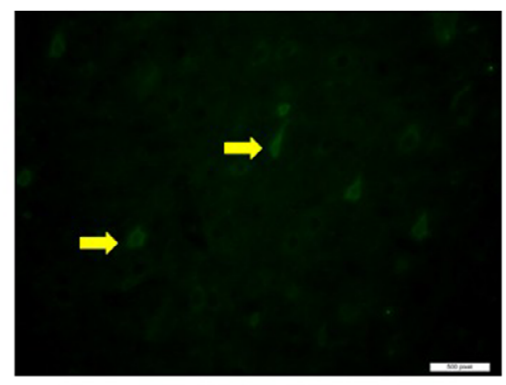

J-1 A+T non-ischemic TUNEL
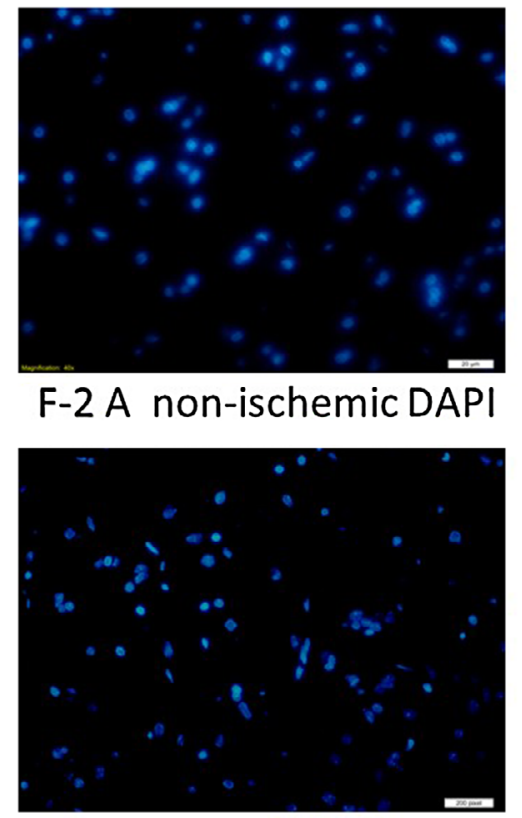

G-2 T ischemic DAPI

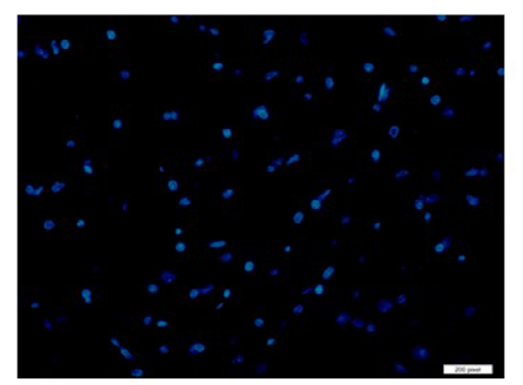

H-2 T non-ischemic DAPI

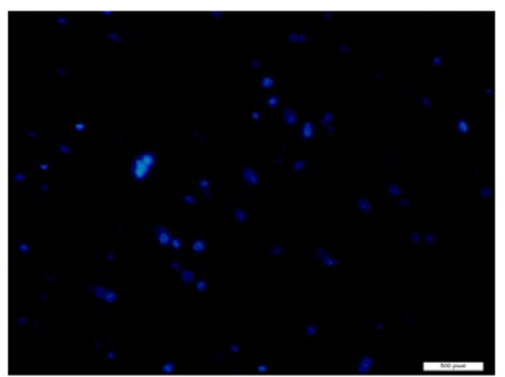

I-2 A+T ischemic DAPI

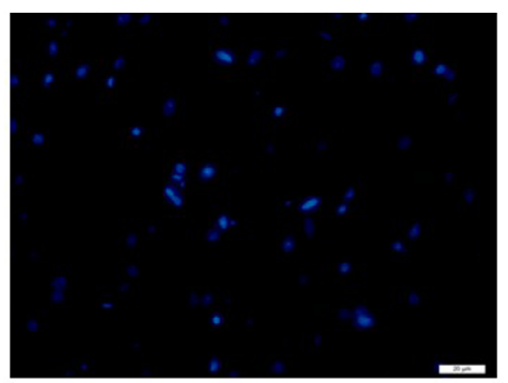

J-2 A+T non-ischemic DAPI

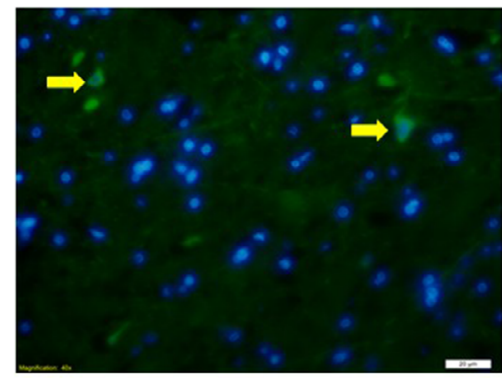

F-3 A non-ischemic merge

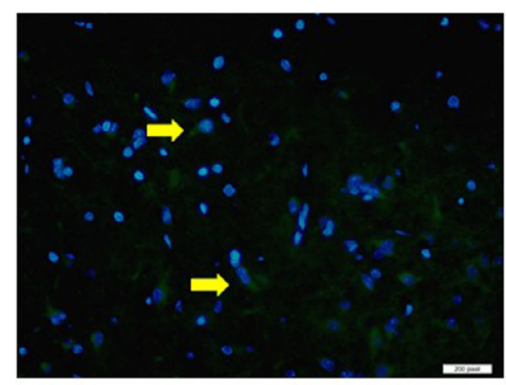

G-3 T ischemic merge

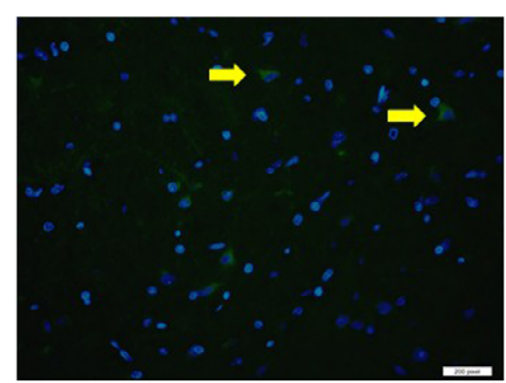

H-3 T non-ischemic merge

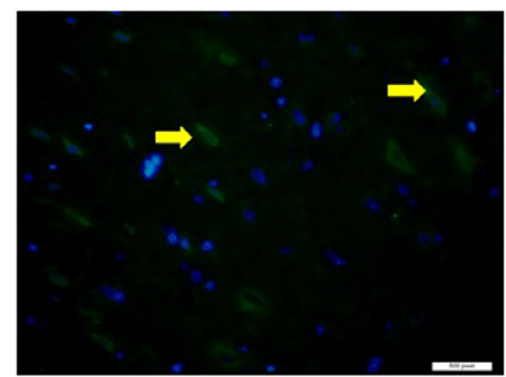

$\mathrm{I}-3 \mathrm{~A}+\mathrm{T}$ ischemic merge

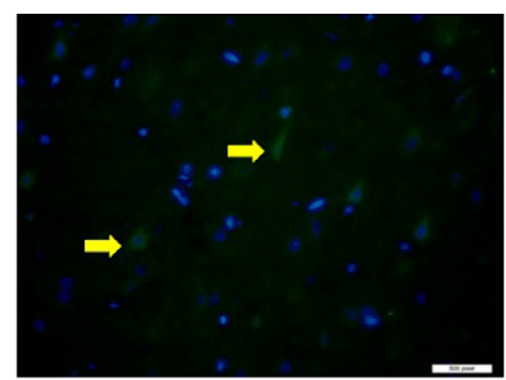

J-3 A+T non-ischemic merge

A - amantadine; $\mathrm{T}$ - topiramate

Fig. 4. Frontal cortex TUNEL (apoptosis), DAPI (nuclear marker) and merge (TUNEL+DAPI) images. F. 1,2,3 - amantadine non-ischemic TUNEL, DAPI, merge; G. 1,2,3 - topiramate ischemic TUNEL, DAPI, merge; H. 1,2,3 - topiramate non-ischemic TUNEL, DAPI, merge; I. 1,2,3 - amantadine + topiramate ischemic TUNEL, DAPI, merge; J. 1,2,3 - amantadine + topiramate non-ischemic TUNEL, DAPI, merge. * yellow arrows indicate TUNEL-positive cells 
added to the blank well. The ELISA plates were incubated in an incubator (Memmert, Schwabach, Germany) at $37^{\circ} \mathrm{C}$ for $60 \mathrm{~min}$. The wash solution was diluted $\times 30$ with distilled water. Each well was washed 5 times with $350 \mu \mathrm{L}$ of wash solution. Next, $50 \mu \mathrm{L}$ of chromogen A and chromogen B were added to each well. Plates were incubated for $10 \mathrm{~min}$ at $37^{\circ} \mathrm{C}$ to ensure coloration. To stop the reaction, $50 \mu \mathrm{L}$ of stopping solution was added to each well. Absorbance was measured at $450 \mathrm{~nm}$ using an ELISA reader (Clariostar, Ortenberg, Germany). The linear regression equation of the standard curve was calculated according to the concentrations of the standards and their respective optical density (OD) values. Lastly, according to the OD value of the sample, the concentration was calculated.

The ischemia-modified albumin (IMA) level was measured using another ELISA kit (Bioassay Technology Laboratory, Shanghai, China). For this assay, $50 \mu \mathrm{L}$ of sample, $50 \mu \mathrm{L}$ of standard and $50 \mu \mathrm{L}$ of biotinylated antigen were sequentially added to 96-well ELISA plates previously coated with antibody and incubated for $30 \mathrm{~min}$. The wash solution was diluted $\times 25$ with distilled water. Each well was washed 5 times with $300 \mu \mathrm{L}$ of wash solution. Next, $50 \mu \mathrm{L}$ of avidin-HRP was added to the sample and standard wells, and the plates were incubated for $30 \mathrm{~min}$. Each well was again washed 5 times with $300 \mu \mathrm{L}$ of wash solution. Next, $50 \mu \mathrm{L}$ of chromogen A and chromogen B were added to each well, and plates were incubated for $10 \mathrm{~min}$ at $37^{\circ} \mathrm{C}$ to ensure coloration. To stop the reaction, $50 \mu \mathrm{L}$ of stopping solution was added to each well. Absorbance at $450 \mathrm{~nm}$ was measured using an ELISA reader. The linear regression equation of the standard curve was calculated according to the concentrations of the standards and their respective OD values. Lastly, according to the OD value of the sample, the concentration was calculated.

\section{Statistical analyses}

The maximum number of animals for each group was calculated to be 5, using the sample size resource equation method. Considering the possibility of loss of animals due to death or injury, 6 animals were included in each group (30 animals in total). SPSS v. 15 software (SPSS Inc., Chicago, USA) was used for all statistical analyses. Numerical data are reported as the median $(\mathrm{Me})$ value and the minimum and maximum (min-max) values. Since our data did not satisfy the assumptions for parametric tests, the Kruskal-Wallis test was used to compare all groups. When a statistically significant difference was detected with the Kruskal-Wallis test, pairwise comparisons were then performed using a Bonferroni-corrected Mann-Whitney U test. A value of $\mathrm{p}<0.05$ was considered statistically significant.

\section{Results}

Regarding the rate of apoptosis in the ischemic right hemispheres, there was no statistically significant difference in the $\mathrm{T}$ and $\mathrm{C}$ groups. However, in the $\mathrm{S}$ and $\mathrm{A}$ groups, the rate was significantly higher than in the non-ischemic left hemisphere $(\mathrm{p}=0.0090)$. Apoptotic cell counts showed no statistically significant difference between the ischemic and non-ischemic samples from the T and AT groups (Table 1, Fig. 3,4). When comparing apoptosis in the ischemic hemispheres of the groups, an increased rate of apoptosis was found in the A and S groups compared with the C group ( $p=0.0020)$. When the left hemispheres without ischemia were compared, it was found that the apoptotic cell count was not significantly different between the groups (Table 2).

The serum TAS level was significantly lower in the AT group compared to all the other groups. No significant differences were noted among other groups. The A group had the highest TAS value in the non-ischemic hemisphere samples, and this value was significantly different from those of the $\mathrm{T}, \mathrm{S}$ and $\mathrm{C}$ groups. In addition, the value in the $\mathrm{T}$ group was significantly higher than that in the $S$ group. The TAS values in the ischemic hemisphere samples were higher in all test groups compared to the $\mathrm{C}$ group, but only the value in the $\mathrm{A}$ group was significantly different (Table 3).

There were no significant differences in the serum and non-ischemic hemisphere TOS values in the test groups compared to the $\mathrm{C}$ group. The ischemic hemisphere TOS values were higher in all test groups compared to the $\mathrm{C}$ group, but only the $\mathrm{T}$ group showed a statistically significant difference (Table 3 ).

Table 1. TUNEL method (apoptotic cell counts) in ischemic and non-ischemic group (in-group comparison; Mann-Whitney $U$ test was used for pairwise comparison)

\begin{tabular}{|l|c|c|c|c|}
\hline \multicolumn{1}{|c|}{ Groups } & $n$ & $\begin{array}{c}\text { Ischemia } \\
\text { Me value } \\
\text { (min-max) }\end{array}$ & $\begin{array}{c}\text { Non-ischemia } \\
\text { Me value } \\
\text { (min-max) }\end{array}$ \\
\hline Group C & 6 & $0.06(0.04-0.13)$ & $0.046(0.037-0.063)$ \\
\hline Group S & 6 & $0.18(0.16-0.19)$ & $0.073(0.047-0.098)$ \\
\hline Group A & 6 & $0.18(0.17-0.22)$ & $0.083(0.05-0.129)$ \\
\hline Group T & 6 & $0.16(0.12-0.19)$ & $0.07(0.053-0.098)$ \\
\hline Group AT & 6 & $0.13(0.12-0.14)$ & 0.0090 \\
\hline
\end{tabular}

Me - median; C - control; S - sham; A - amantadine; T - topiramate; AT - amantadine-topiramate. 
Table 2. TUNEL method (apoptotic cell counts) in ischemic and non-ischemic group (intergroup comparison)

\begin{tabular}{|c|c|c|c|c|c|c|}
\hline Parameters & Groups & $\mathrm{N}$ & $\begin{array}{l}\text { Me value } \\
(\min -\max )\end{array}$ & $x^{2}$ & df & $p$-value \\
\hline Ischemic & $\begin{array}{l}\text { group C } \\
\text { group S } \\
\text { group A } \\
\text { group T } \\
\text { group AT }\end{array}$ & $\begin{array}{l}6 \\
6 \\
6 \\
6 \\
6\end{array}$ & $\begin{array}{l}0.06(0.04-0.13) \\
0.18(0.16-0.19) \\
0.18(0.17-0.22) \\
0.16(0.12-0.19) \\
0.13(0.12-0.14)\end{array}$ & 16.992 & 4 & 0.0020 \\
\hline \multicolumn{7}{|c|}{$\begin{array}{l}\text { groups } C \text { and } S, p=0.0090 \text { (adjusted } p \text {-value }=0.0900 \text { ) } \\
\text { groups } C \text { and } A, p=0.0090 \text { (adjusted } p \text {-value }=0.0900 \text { ) }\end{array}$} \\
\hline Non-ischemic & $\begin{array}{l}\text { group C } \\
\text { group S } \\
\text { group A } \\
\text { group T } \\
\text { group AT }\end{array}$ & $\begin{array}{l}6 \\
6 \\
6 \\
6 \\
6\end{array}$ & $\begin{array}{c}0.046(0.037-0.063) \\
0.073(0.047-0.098) \\
0.083(0.05-0.129) \\
0.07(0.053-0.098) \\
0.076(0.038-0.087)\end{array}$ & 9.193 & 4 & 0.0560 \\
\hline
\end{tabular}

The adjusted $\mathrm{p}$-value is the $\mathrm{p}$-value after the Bonferroni correction. Me - median; $\mathrm{df}$ - degrees of freedom; C - control; S - sham; A - amantadine; T - topiramate; AT - amantadine-topiramate.

Table 3. Comparison of serum and pathological tissue of total antioxidant status (TAS), total oxidant status (TOS), thiol, and ischemia-modified albumin (IMA) values of whole groups

\begin{tabular}{|c|c|c|c|c|c|c|c|c|c|c|}
\hline \multirow[b]{2}{*}{ Tests } & \multirow[b]{2}{*}{ Groups } & \multirow[b]{2}{*}{$\mathrm{N}$} & \multicolumn{4}{|c|}{ Serum } & \multicolumn{4}{|c|}{ Pathologic tissue } \\
\hline & & & $\begin{array}{l}\text { Me value } \\
\text { (min-max) }\end{array}$ & $x^{2}$ & df & $\mathrm{p}$-value & $\begin{array}{l}\text { Me value } \\
\text { (min-max) }\end{array}$ & $x^{2}$ & df & $\mathrm{p}$-value \\
\hline \multirow[t]{7}{*}{ TAS } & & & & 12.095 & 4 & 0.0172 & & 14.821 & 4 & 0.0050 \\
\hline & group C & 6 & 8.04 (7.48-9.97) & & & & $7.6(7.26-8.54)$ & & & \\
\hline & group S & 6 & $6.14(5.77-15.29)$ & & & & $10.66(7.26-12.51)$ & & & \\
\hline & group A & 6 & $8.57(6.43-10.93)$ & & & & $11.16(9.13-13.08)$ & & & \\
\hline & group $T$ & 6 & $7.38(6.53-9.67)$ & & & & $9.31(8.54-10.34)$ & & & \\
\hline & group AT & 6 & $5.15(3.97-5.29)$ & & & & $13.21(11.32-14.13)$ & & & \\
\hline & & & \multicolumn{4}{|c|}{$\begin{array}{l}\text { groups } C \text { and } A T, p=0.0140, \text { adjusted } p=0.1400 \\
\text { groups } S \text { and } A T, p=0.0140, \text { adjusted } p=0.1400 \\
\text { groups } A \text { and } A T, p=0.0140, \text { adjusted } p=0.1400 \\
\text { groups } T \text { and } A T, p=0.0140, \text { adjusted } p=0.1400\end{array}$} & \multicolumn{4}{|c|}{ groups $C$ and $A, p=0.0090$, adjusted $p$-value $=0.0900$} \\
\hline \multirow[t]{7}{*}{ TOS } & & & & 5.073 & 4 & 0.2800 & & 13.796 & 4 & 0.0080 \\
\hline & group C & 6 & $5.91(5.59-6.68)$ & & & & $1.32(1.26-5.63)$ & & & \\
\hline & group S & 6 & $8.52(5.85-20.41)$ & & & & $4.67(2.76-8.45)$ & & & \\
\hline & group A & 6 & $7.98(1.23-11.57)$ & & & & $7.91(5.36-9.32)$ & & & \\
\hline & group T & 6 & $6.84(6.32-7.35)$ & & & & $9.11(6.66-11.75)$ & & & \\
\hline & group AT & 6 & $6.77(5.73-8.11)$ & & & & $7.6(6.55-11.75)$ & & & \\
\hline & & & & & & & \multicolumn{4}{|c|}{ groups $C$ and $T, p=0.0090$, adjusted $p$-value $=0.0900$} \\
\hline \multirow[t]{7}{*}{ Thiol } & & & & 5.716 & 4 & 0.2210 & & 10.700 & 4 & 0.0300 \\
\hline & group C & 6 & $4.39(2.54-6.21)$ & & & & $18.38(14.61-26.43)$ & & & \\
\hline & group S & 6 & $5.6(2.55-11.07)$ & & & & $9.36(4.34-18.07)$ & & & \\
\hline & group A & 6 & $8.51(2.72-11.74)$ & & & & $4.92(2.94-17.12)$ & & & \\
\hline & group T & 6 & $10.51(3.15-28.96)$ & & & & $10.17(7.36-21.54)$ & & & \\
\hline & group AT & 6 & $11.43(6.75-16.71)$ & & & & $6.73(4.62-9.81)$ & & & \\
\hline & & & & & & & \multicolumn{4}{|c|}{ groups $C$ and $A T, p=0.0140$, adjusted $p$-value $=0.1400$} \\
\hline \multirow[t]{6}{*}{ IMA } & & & & 4.281 & 4 & 0.3690 & & 3.617 & 4 & 0.4600 \\
\hline & group C & 6 & $3.84(2.32-14.51)$ & & & & $19.35(14.81-39.58)$ & & & \\
\hline & group S & 6 & $10.39(6.31-12.56)$ & & & & $30.65(24.56-33.63)$ & & & \\
\hline & group A & 6 & $9.52(2.75-11.19)$ & & & & $20.64(16.37-28.62)$ & & & \\
\hline & group $T$ & 6 & $7.56(4.02-10.47)$ & & & & $21.98(12.85-28.62)$ & & & \\
\hline & group AT & 6 & $4.05(2.74-4.49)$ & & & & $20.01(15.93-39.25)$ & & & \\
\hline
\end{tabular}

The adjusted $p$-value is the $\mathrm{p}$-value after the Bonferroni correction. Me - median value; df - degree of freedom; TAS - total antioxidant status; TOS - total oxidant status; IMA - ischemia-modified albumin; C - control; S - sham; A - amantadine; T - topiramate; AT - amantadine-topiramate. 
There was no difference in serum total thiol values between groups. The A group had the lowest thiol value in the non-ischemic hemispheric tissue samples, but this level was only significantly different when compared to that in the $\mathrm{T}$ and $\mathrm{S}$ groups. All total thiol values in the ischemic hemisphere samples of the test groups were lower compared to that in the $\mathrm{C}$ group, but only the value in the AT group was significantly different (Table 3 ).

Regarding IMA levels, the $C$ group had the lowest IMA level while the $S$ group had the highest. The IMA values in the $\mathrm{AT}$ group were closest to those in the $\mathrm{C}$ group, but the difference was not statistically significant (Table 3).

\section{Discussion}

Cerebrovascular disease remains an important cause of morbidity and mortality worldwide. Many factors contribute to the etiology of cerebrovascular disease. Currently, the most effective treatments for stroke are control of correctable risk factors and prophylactic use of anti-aggregant/anticoagulant therapy. The probability of successful treatment is limited after ischemia develops. Neurons that die within minutes in ischemic tissue and the penumbra, which is the recoverable area around these neurons, are defined as treatment targets. Recently, thrombolytic treatment and endovascular treatment options have been developed to target the penumbra; they correct tissue perfusion in the hyperacute period and prevent tissue damage in the early period. ${ }^{9}$ These treatments ultimately aim to reduce mortality and morbidity. However, options for treating the ischemic nucleus, where cells rapidly die, have not yet been developed. To address this, the mechanisms of the pathophysiological events occurring in ischemic neurons must first be clearly understood. Although previous studies suggest that apoptosis is a key factor for damage (it develops in response to acute ischemic damage and is triggered by factors such as the overproduction of free radicals, $\mathrm{Ca}_{2}{ }^{+}$overload and excitotoxicity), complete details of the processes leading to apoptosis remain unknown. Changes in cellular homeostasis can trigger necrosis or apoptosis; the choice of path usually depends on the cell type, cell age and its location in the brain. Apoptosis leads to degradation of DNA and cytoskeleton and nuclear proteins, crosslinking of proteins, formation of apoptotic bodies, expression of ligands for phagocytic cell receptors, and retention by phagocytic cells. ${ }^{9}$

Research focusing on the events that initiate apoptosis, namely ischemia triggering an increase in intracellular $\mathrm{Ca}_{2}+$, has recently gained momentum. Some neurotransmitters and neuromodulators are known to contribute to ischemic stroke damage and neuron death. Excitatory amino acid receptor activation, $\mathrm{Ca}^{+}$overload, nitric oxide (NO), and oxidative stress are all well-known steps in the pathogenesis of ischemia. In a study testing the hypothesis that an increase in gamma-aminobutyric acid (GABA) receptor activity may prevent NMDA receptor-mediated NO production and decrease brain damage, the results showed that both the GABA (A) receptor agonist muscimol and GABA (B) receptor agonist baclofen had neuroprotective effects. Neurons treated with a combination of the 2 agonists were found to have reduced ischemia, suggesting that these agonists can significantly protect against neuronal death caused by reperfusion. ${ }^{10}$

An important factor determining the response of a cell to apoptotic mechanisms is the form of stress, which includes hypoxia, energy deprivation, DNA damage, and inflammation. The duration and intensity of stress also guide the response of a cell and adaptation to stress. A cell may survive stress and heal, or may die via apoptosis, necrosis or autophagy. ${ }^{11}$ In our study, an increase in apoptosis was observed in the non-ischemic hemisphere samples of all test groups compared to the $\mathrm{C}$ group. This finding suggests that ischemia can trigger apoptosis in the ischemic hemisphere and in the opposite hemisphere due to the stress it generates.

As predicted, the lowest amount of apoptosis in the ischemic hemisphere was recorded in the $C$ group. The AT group had an apoptosis value that was most similar to that of the $\mathrm{C}$ group, but only the $\mathrm{S}$ and $\mathrm{A}$ group values were significantly different from that of the $C$ group. In our study, amantadine had no effect on apoptosis in the acute period after ischemia was induced.

Amantadine is a dopamine D2 receptor agonist. Since it is also an NMDA receptor antagonist, its effect on healing after traumatic brain injury has been the subject of several studies. Although no serious adverse effects have been reported, some studies could not show a significant effect compared to a control group. Therefore, an experimental traumatic brain injury model was created in a previous study to test whether this inconsistency was the result of the evaluation criteria or the differences in the doses used: daily doses of $20 \mathrm{mg} / \mathrm{kg}$ and $40 \mathrm{mg} / \mathrm{kg}$ were administered intraperitoneally for 19 days. The study showed that amantadine improved motor and cognitive performance, emphasizing that amantadine showed efficacy in a dosedependent manner. ${ }^{12}$

However, the mechanism of the neuroprotective efficacy of amantadine is still unclear. In rats, corticosteroneinduced abnormal glutamatergic synaptic transmission in the hippocampal region has been observed to significantly improve when the release of spontaneous glutamate from presynaptic terminals is modulated and when oxidative stress is reduced by decreasing intracellular $\mathrm{Ca}^{+}$ increases. $^{13}$

In our study, amantadine was used in rats at a dose of $20 \mathrm{mg} / \mathrm{kg} /$ day in accordance with the literature, but its effectiveness on apoptosis could not be demonstrated. This may be due to the fact that its efficacy at the tissue level was assessed $24 \mathrm{~h}$ after acute ischemic injury. These results may indicate that amantadine has no effect on apoptosis 
in the acute period. Thus, studies of its longer-term use are warranted.

The anti-dyskinetic activity of amantadine in clinical Parkinson's disease is well-known. A study of a Parkinson's disease animal model demonstrated that the combined use of amantadine and topiramate had synergistic effects on dyskinesia, without adverse motor effects. ${ }^{14}$ This report strongly influenced our study - we aimed to determine if amantadine and topiramate had the same synergistic effect in the ischemia-reperfusion model. Although the rate of apoptosis in ischemic tissue samples increased significantly in the A group compared to the $S$ group, it did not differ significantly in the $T$ and AT groups compared to the $C$ group. The apoptosis rate in the AT group, compared to the $\mathrm{T}$ group, was closer in value to that of the $C$ group; however, the difference was not statistically significant. In future studies with more subjects, the issue of whether amantadine increases the antiapoptotic properties of topiramate should be further examined.

Although topiramate is less effective than memantine in hypoxic ischemic encephalopathy models in vivo and in vitro, it has been shown to decrease cerebral damage, especially in combination with hypothermia. ${ }^{6}$ Recent studies that investigated the actions of topiramate on ventrolateral periaqueductal gray (vlPAG) glutamatergic transmission and aggressive behaviors in rats suggested that a single injection of topiramate systemically and dose-dependently inhibited elements of offensive aggressive behaviors. ${ }^{15}$ There are additional reports indicating that, in rats, topiramate (at $30 \mathrm{mg} / \mathrm{kg} /$ day) decreases hippocampal cell loss after hypoxia, prevents memory impairment and aggres$\operatorname{sion}^{16}$ and reduces apoptosis in the hippocampus against hyperoxic damage (at $80 \mathrm{mg} / \mathrm{kg} /$ day). ${ }^{17}$

The dose range of topiramate reported in previous experimental studies is broad and often depends on the method of administration. For example, the efficacy of topiramate at a dose of 40-160 mg/kg/day in an inflammatory hyperalgesia model in rats ${ }^{18}$ was demonstrated, and at a dose of $40 \mathrm{mg} / \mathrm{kg} / \mathrm{day}^{19}$ in studies on behavioral symptoms in rats. It has also been reported that hippocampal ischemic neuronal damage almost eliminates all histological findings. ${ }^{20}$

In experimental studies, topiramate has been reported to effectively reduce intracranial pressure in rats, even at much lower doses (oral delivery of $6.25 \mathrm{mg} / \mathrm{kg}$ ). ${ }^{21}$ Thus, it can be hypothesized that topiramate may provide additional benefits in cerebral ischemia-reperfusion models, because one of the parameters that adversely affects the clinical condition after ischemia is the increase of edema in ischemic tissue.

In our study, we observed that topiramate, when administered intraperitoneally at a dose of $40 \mathrm{mg} / \mathrm{kg}$, significantly reduced apoptosis. In a study that examined patients with ischemic and hemorrhagic stroke, it was reported that the risk of seizures was higher after hemorrhagic stroke and $10 \%$ of patients with stroke will develop seizures within a decade. ${ }^{22}$ However, there are currently no clear data supporting routine prophylactic antiepileptic use in stroke patients. ${ }^{23}$ When acute period antiepileptic drugs are selected for stroke patients, the positive effects of topiramate should be taken into consideration, namely, its ability to decrease intracranial pressure and apoptosis in ischemic tissue.

Post-stroke oxidative stress is thought to play a role in brain damage through the release of a significant amount of oxygen-free radicals. For example, the n-terminal of human serum albumin is unstable and more prone to deterioration during oxidative stress; a reduction in binding capacity has been observed for transition metals, such as $\mathrm{Cu}$ and $\mathrm{Co}$, and this form is called IMA. It has been reported that IMA levels increase in ischemic events, such as acute myocardial infarction and cerebrovascular events. ${ }^{24}$ However, the increase in IMA is not tissue-specific and has been demonstrated to vary according to the duration of ischemia. ${ }^{25}$ Furthermore, IMA increases are not specific to ischemic events. The IMA levels have also been shown to increase in obstructive sleep apnea ${ }^{26}$ and during pregnancy, which is a physiological event. ${ }^{27}$ Notably, smokers showed no increase in IMA levels compared to a control group. ${ }^{28}$

In our study, there were no significant differences in IMA levels in the blood, ischemic tissue or non-ischemic tissue samples from the test groups compared to the $C$ group or between test groups. A previous study reported IMA levels in 118 patients who had blood samples taken within $3 \mathrm{~h}$ of the onset of acute neurological deficits. These patients were divided into 3 groups: cerebral ischemia; hemorrhage and transient ischemic attack (TIA); or transient neurological deficit, which could not be clearly differentiated from epileptic seizure. In the first evaluation, no significant difference was observed between the groups with ischemia or hemorrhage, whereas both of these groups showed significant elevation compared to the group with temporary neurological deficits. These results suggest that the lack of change in IMA levels in our study were not due to the short duration of our ischemia-reperfusion model. In addition, the same study revealed that the IMA levels at $24 \mathrm{~h}$ in the ischemia group patients continued to be significantly different from those in the hemorrhagic group patients. $^{29}$

Another indicator of oxidative stress is deterioration of the thiol-disulfide balance. In cerebrovascular events, this balance is disrupted. Total thiol and natural thiol levels have been reported to be significantly lower in patients with cerebral venous sinus thrombosis $(n=38)$ than in healthy volunteers $(n=80) .{ }^{30}$ In experimental global and focal ischemia-reperfusion models, a decrease in thiol levels after ischemia has been reported. ${ }^{31}$

In the present study, no statistically significant difference was observed in blood total thiol levels between groups. In the ischemic tissue samples, the total thiol levels were 
lower in all test groups than in the $\mathrm{C}$ group, but there was a statistically significant difference only in the AT group. This finding can be interpreted to mean that amantadine does not have a positive effect on oxidative stress, as evaluated using total thiol levels.

Furthermore, there was no significant difference in the serum TOS values in the test groups compared to the $C$ group. In the tissue samples, the TOS value was lowest in the $C$ group, as expected. Only the value in the $\mathrm{T}$ group was significantly different. It was also observed that topiramate had no positive effect on the TOS value and that amantadine and amantadine-topiramate combination therapy had no benefit over the isotonic group.

Regarding the serum TAS values, the only group that differed significantly from the $C$ group was the AT group. A significant decrease in the serum TAS value was observed in this group. The lowest TAS value in the tissue samples was found in the $\mathrm{C}$ group. Although the value in the $\mathrm{T}$ group was most similar to that in the $\mathrm{C}$ group, the only significant difference was between the $\mathrm{A}$ and $\mathrm{C}$ groups. Thus, it was determined that amantadine did not have a positive effect on ischemia-induced TAS level and noted that the amantadine-topiramate combination did not have a significant effect compared to the $S$ group.

As a result, we were unable to demonstrate a positive effect on the oxidative stress parameters with the isolated or combined use of these agents. This may have been due to the short length of exposure to ischemia or because oxidative stress was assessed after $24 \mathrm{~h}$. Longer exposure to ischemia, use of different oxidative stress parameters, or evaluation of samples collected during the hyperacute or subacute periods may have different results. All of these issues are open to discussion.

Due to the increased rate of apoptosis after $10 \mathrm{~min}$ of ischemia, it may be stated that this short exposure to ischemia is sufficient for triggering cell death. However, it may be necessary to explain the course of cell death in this acute period by mechanisms other than oxidative stress. Our study showed that administration of topiramate, which had no significant effect on IMA, TAS, TOS, or total thiol levels, resulted in reduced apoptosis compared to the $C$ group. In future studies, the positive effects of topiramate on ischemia-induced neuronal damage should be evaluated using different biomarkers to investigate different mechanisms.

\section{Limitations}

Several limitations of our study should be noted. First of all, the duration of ischemia could be prolonged by longer occlusion of the internal carotid artery. Secondly, the duration of administration of amantadine and topiramate could be extended. Either of these changes could affect the results.

\section{Conclusions}

Tissue damage in ischemic stroke cannot be fully explained by hypoperfusion and acute cell death due to hypoxia. The inflammatory response developed by ischemic tissue is also responsible for cell damage. Currently, the best known treatments are those that prevent ischemia. Thrombolytic and endovascular treatment options, which have recently become widespread, have significantly reduced poststroke morbidity and mortality rates. These treatments provide reperfusion at the tissue level and act by restoring the penumbra, but they cannot save neurons that die within minutes after ischemia. Clarifying the pathophysiological events that develop in the ischemic process will play an important role in the development of treatments aimed at reducing ischemic damage at the cell level. Our study shows that topiramate reduces apoptosis in the early postischemia period and that its combination with amantadine does not provide additional benefits for reducing cell death. Topiramate did not have an inhibitory effect on the oxidative stress biomarkers used in our study (TAS, TOS, IMA, and thiol). Studies that reveal the neuroprotective mechanism of action and long-term effects of topiramate are needed to complement the findings of this study.

\section{ORCID iDs}

Zahide Betül Gündüz (D) https://orcid.org/0000-0002-6421-1857 Filiz Aktas (D) https://orcid.org/0000-0003-2973-916X Husamettin Vatansev (D https://orcid.org/0000-0002-0230-3414 Merve Solmaz (1) https://orcid.org/0000-0003-4144-4647 Ender Erdoğan (D) https://orcid.org/0000-0002-6220-9243

\section{References}

1. Broughton BR, Reutens DC, Sobey CG. Apoptotic mechanisms after cerebral ischemia. Stroke. 2009;40(5):331-339. doi:10.1161/STROKE AHA.108.531632

2. Ozdemir HH, Demir CF, Berilgen MS, et al. Protective effects of memantine induced by cerebral ischemia and reperfusion injury in rats. Turk J Neurol. 2013;19(3):85-89. doi:10.4274/Tnd.85866

3. Giacino JT, Whyte J, Bagiella E, et al. Placebo-controlled trial of amantadine for severe traumatic brain injury. N Engl J Med. 2012;366(9): 819-826. doi:10.1056/NEJMoa1102609

4. Farrell D, Bendo AA. Perioperative management of severe traumatic brain injury: What is new? Curr Anesthesiol Rep. 2018;8(3):279-289. doi:10.1007/s40140-018-0286-1

5. Sawyer E, Mauro LS, Ohlinger MJ. Amantadine enhancement of arousal and cognition after traumatic brain injury. Ann Pharmacother. 2008; 42(2):247-252. doi:10.1345/aph.1K284

6. Landucci E, Filippi L, Gerace E, Catarzi S, Guerrini R, PellegriniGiampietro DE. Neuroprotective effects of topiramate and memantine in combination with hypothermia in hypoxic-ischemic brain injury in vitro and in vivo. Neurosci Lett. 2018;668:103-107. doi:10.1016/j. neulet.2018.01.023

7. Narin F, Hanalioglu S, Ustun H, Kilinc K, Bilginer B. Topiramate as a neuroprotective agent in a rat model of spinal cord injury. Neural Regen Res. 2017;12(12):2071-2076. doi:10.4103/1673-5374.221164

8. Garcia JH. Experimental ischemic stroke: A review. Stroke. 1984;15(1): 5-14. doi:10.1161/01.str.15.1.5

9. Radak D, Katsiki N, Resanovic l, et al. Apoptosis and acute brain ischemia in ischemic stroke. Curr Vasc Pharmacol. 2017;15(2):115-122. doi:10. 2174/1570161115666161104095522

10. Tuttolomondo A, Di Sciacca R, Di Raimondo D, et al. Neuron protection as a therapeutic target in acute ischemic stroke. Curr Top Med Chem. 2009;9(14):1317-1334. doi:10.2174/156802609789869646 
11. Milisav I, Poljšak $B$, Ribarič $S$. Reduced risk of apoptosis: Mechanisms of stress responses. Apoptosis. 2017;22(2):265-283. doi:10.1007/ s10495-016-1317-3

12. Okigbo AA, Helkowski MS, Royes BJ, et al. Dose-dependent neurorestorative effects of amantadine after cortical impact injury. Neurosci Lett. 2019;694:69-73. doi:10.1016/j.neulet.2018.11.030

13. Xiao X, Zhang H, Wang H, Li Q, Zhang T. Neuroprotective effect of amantadine on corticosterone-induced abnormal glutamatergic synaptic transmission of CA3-CA1 pathway in rat's hippocampal slices [Epub ahead of print]. Synapse. 2017;71(12):10. doi:10.1002/syn.22010

14. Kobylecki C, Hill MP, Crossman AR, Ravenscroft P. Synergistic antidyskinetic effects of topiramate and amantadine in animal models of Parkinson's disease. Mov Disord. 2011;26(13):2354-2363. doi:10. 1002/mds. 23867

15. Chou D. Topiramate inhibits offensive aggression through targeting ventrolateral periaqueductal gray. Neuropharmacology. 2020:181: 108361. doi:10.1016/j.neulet.2018.01.023

16. Mikati MA, Daderian R, Zeinieh M, Leonard AS, Azzam D, Kurdi R. Potential neuroprotective effects of continuous topiramate therapy in the developing brain. Epilepsy Behav. 2011;20(4):597-601. doi:10. 1016/j.yebeh.2010.12.011

17. Kurul $\mathrm{SH}, \mathrm{Yiş} \mathrm{U}, \mathrm{Kumral} \mathrm{A}$, et al. Protective effects of topiramate against hyperoxic brain injury in the developing brain. Neuropediatrics. 2009;40(1):22-27. doi:10.1055/s-0029-1224101

18. Paranos SL, Tomić MA, Micov AM, Stepanović-Petrović R. The mechanisms of antihyperalgesic effect of topiramate in a rat model of inflammatory hyperalgesia. Fundam Clin Pharmacol. 2013;27(3):319-328. doi:10.1111/j.1472-8206.2011.01018.x

19. Junqueira-Ayres DD, Asth L, Ayres AS, Lobão-Soares B, SoaresRachetti VP, Gavioli EC. Topiramate reduces basal anxiety and relieves ethanol withdrawal-induced anxious behaviors in male rats. Exp Clin Psychopharmacol. 2017;25(2):105-113. doi:10.1037/pha0000118

20. Edmonds HL Jr, Jiang YD, Zhang PY, Shank R. Topiramate as a neuroprotectant in a rat model of global ischemia-induced neurodegeneration. Life Sci. 2001;69(19):2265-2277. doi:10.1016/s0024-3205 (01)01306-6
21. Scotton WJ, Botfield HF, Westgate CS, et al. Topiramate is more effective than acetazolamide at lowering intracranial pressure. Cephalalgia. 2019;39(2):209-218. doi:10.1177/0333102418776455

22. Merkler AE, Gialdini G, Lerario MP, et al. Population-based assessment of the long-term risk of seizures in survivors of stroke. Stroke. 2018;49(6):1319-1324. doi:10.1161/STROKEAHA.117.020178

23. Tanaka T, Ihara M. Post-stroke epilepsy. Neurochem Int. 2017;107:219228. doi:10.1016/j.neuint.2017.02.002

24. Menon B, Ramalingam K, Krishna V. Study of ischemia-modified 24-albumin as a biomarker in acute ischaemic stroke. Ann Neurosci. 2018;25(4):187-190. doi:10.1159/000488188

25. Nayak AR, Kashyap RS, Kabra D, Purohit HJ, Taori GM, Daginawala HF. Prognostic significance of ischemia-modified albumin in acute ischemic stroke patients: A preliminary study. Ann Neurosci. 2011;18(1):5-7. doi:10.5214/ans.0972.7531.1118103

26. Sunnetcioglu A, Asker S, Alp HH, Gunbatar H. Increased asymmetric dimethylarginine and ischemia-modified albumin levels in obstructive sleep apnea. Respir Care. 2016;61(8):1038-1043. doi:10.4187/respcare. 04472

27. Bahinipati J, Mohapatra PC. Ischemia-modified albumin as a marker of oxidative stress in normal pregnancy. J Clin Diagn Res. 2016;10(9): 15-17. doi:10.7860/JCDR/2016/21609.8454

28. Battal F, Tekin M, Aylanç H, et al. Serum ischemia-modified albumin levels in adolescent smokers. Int J Adolesc Med Health. 2016;30(1):1-5. doi:10.1515/ijamh-2015-0128

29. Abboud H, Labreuche J, Meseguer E, et al. Ischemia-modified albumin in acute stroke. Cerebrovasc Dis. 2007;23(2-3):216-220. doi:10. $1159 / 000097644$

30. Vural G, Gumusyayla S, Deniz O, Neselioglu S, Erel O. Thiol-disulfide homeostasis in cerebral venous sinus thrombosis. Clin Lab. 2018; 64(11):10-14. doi:10.7754/Clin.Lab.2018.180707

31. Ivanov AV, Alexandrin VV, Paltsyn AA, et al. Plasma low-molecularweight thiol/disulphide homeostasis as an early indicator of global and focal cerebral ischaemia. Redox Rep. 2017;22(6):460-466. doi:10. 1080/13510002.2017.1311464 